\title{
Measuring Hardness and Bursting Strength for Paintings
}

\author{
Kholod K Salama ${ }^{1 *}$, Mona F Ali ${ }^{2}$ and Said M El-Sheikh ${ }^{3}$ \\ ${ }^{1}$ National museum of Egyptian civilization, Cairo, Egypt \\ ${ }^{2}$ Conservation Department, Faculty of Archaeology, Cairo university, Egypt \\ ${ }^{3}$ Nano-Structured Materials and Nanotechnology Division, Advanced Materials Department, Egypt
}

Submission: July 28, 2018; Published: August 20, 2019

*Corresponding author: Kholod K Salama, National museum of Egyptian civilization, Cairo, Egypt

Abstract

This paper presents a research results on using different nanomaterials such as (nano calcium hydroxide, nano calcium carbonate, nano silicon dioxide, magnetic nano wire, magnetic nanoparticles, carbon nano tube) then nanomaterials with polymeric material (Beva 371) soluble in toluene/ethanol. The authors have enhanced some existing experimental techniques for testing the effects of such nanomaterials in consolidation in laboratory, using means of tests on non-standard mockup models to identify the success of paintings consolidation treatment. Hardness was tested which express the painting resistance to be penetrated by shore D (Durometer) and that instrument doesn't cause any damage to the surface as it can test the hardness in small inconspicuous place in the painting surface. Bursting strength which express the ability of paintings to bear pressure tested by Tinuis Olsen, that instrument must test mockup models not the original surface.

Keywords: Hardness; Bursting; Consolidation; Paintings

\section{Research Aims}

Discussion the use of different nano materials in consolidation of mock up models of an Egyptian Coptic fresco painting, to compare the results in order to apply the final chosen nanomaterial on the original Coptic fresco painting, show new ways for Testing of consolidated samples and results using Durometer which can be used in small inconspicuous place in the painting surface without any damage to the sample or the original painting itself. And using Tinuis Olsen which must be used with models as the samples were broken after the test.

\section{Introduction}

Many paintings suffered from weakness and fragility so consolidation process aimed to increase the resistance of paintings to the surroundings, previously it was well known that no tests can assure the success of consolidation material but now days mock up models are using as experimental models to get the final results which will be applied on the original monument. that important step in conservation filed need to be assured by testing the new characteristics in the treated models with different nanomaterials using the durometer to define the hardness and Tinuis Olsen to define the bursting strength. All nano materials are producing anew characteristics in the treated models [1].

\section{Materials and Methods}

\section{Materials}

All the chemicals were of analytical grade and were used without further purification. The nano- materials are nanocalcium hydroxide, nano-calcium carbonate, nano silica, magnetic nano particles, magnetic nanowires, carbon nano tube were obtained from nano tech com. LTD. and BEVA 371 is a thermoplastic, elastomeric polymer mixture. It is composed of Elvax (ethylenelvinyl acetate [EVA] copolymer), ketone resin $\mathrm{N}$ (polycyclohexanone), A-C copolymer (EVA), Cellolyn 21 (phthalate ester of hydroabietyl alcohol), and paraffin. It is an opaque gel at room temperature and has a melting point of 50-55 ${ }^{\circ} \mathrm{C}$. It is soluble in naphtha, toluene, acetone, and alcohol. BEVA produces a matte [2], waxy finish and is used as a consolidated for paintings and textiles and it was purchased from Arts Conservation Agency (local company). Water was purified by a Millipore Elix 3 apparatus: the resistance of the ultra-pure water was $18 \mathrm{M} \Omega . \mathrm{cm}$.

\section{Preparation of the Mixed Nano-Material System}

The nanomaterial was sonicated in ultrasonic power 100 for 1 hour to make a homogenous suspension. Preparation of the 


\section{Global Journal of Archaeology \& Anthropology}

mixed nanomaterial / system was carried out via backing of the Coptic fresco paint with $2 \mathrm{gm}$ of nanomaterials dissolved in 98

\section{The Preparation of the Models and Samples}

$\mathrm{ml}$ of isopropanol at room temperature, then the nano-materials suspension in polymeric material (Beva371) [3].

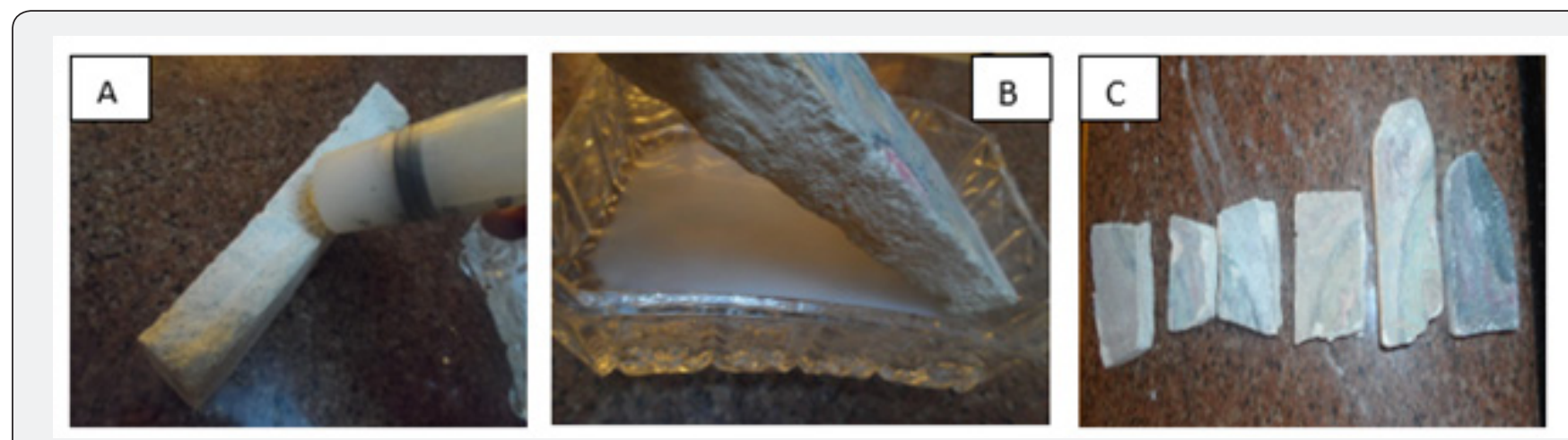

Figure 1: (A-B) Examples of the treatment to samples by injection and immersed. The samples after treatment.

The models prepared according to the original mural painting Which stored in the Coptic museum with registration No 8425, it suffered from weakness as there are a vital crack. The models cut in pieces to be tested after application of different nano- materials (Figure 1).

Testing of Consolidated Samples and Results

\section{Hardness and Bursting}

Hardness: Hardness is expressing the strength of mural paintings to the outside pressures, there are many discoloration methods which causing a big hole in the surface but the Shore D instrument is consider safety methods to test the hardness. As the Shore D scale is based on ASTM D2240. The test involves the use of a hardened steel rod $1.1 \mathrm{~mm}-1.4 \mathrm{~mm}$ diameter, with a $30^{\circ}$ conical point, $0.1 \mathrm{~mm}$ radius tip. This exerts $44.64 \mathrm{~N}$ of force [4] The measured hardness is determined by the penetration depth of the indenter under the load maximum penetration for each scale is $2.5-2.54 \mathrm{~mm}$, the amount of penetration is converted to hardness reading on scale of 100 units maximum hardness value 100 shore corresponds to zero penetration which can be converted in to newton to be $44.45 \mathrm{~N}$ in Table 1 [5] (Figure 2).
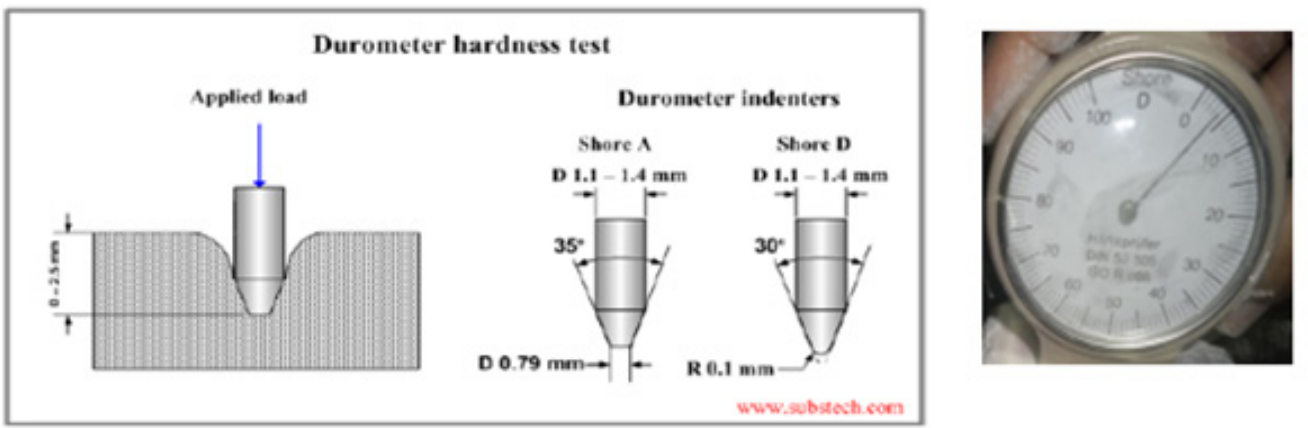

Figure 2: The shore $D$ and the diagram of the way of measurement.

Table 1: The relation between penetration and newton force.

\begin{tabular}{|c|c|c|}
\hline Durometer unit & Penetration $\mathbf{~ m m}$ & Newton Force N \\
\hline 10 & 2.5 & 4.4 \\
\hline 20 & 0.2 & 13.34 \\
\hline 30 & 0.3 & 17.8 \\
\hline 40 & 0.4 & 22.23 \\
\hline 50 & 0.5 & 26.7 \\
\hline 60 & 0.6 & 31.12 \\
\hline
\end{tabular}




\section{Global Journal of Archaeology \& Anthropology}

\begin{tabular}{|c|c|c|}
\hline 90 & 0.9 & 40.01 \\
\hline 100 & 0 & 44.5 \\
\hline
\end{tabular}

*If the hardness 100 the length of indenter =0: The consolidated samples tested by Dorometer in inconspicuous place in the sample surface ,The hardness of Sample before treatment in range 15-19 but after treatment and the application of nano calcium hydroxide increase the hardness to 35-47 and after application of nano calcium carbonate the hardness became
45 , with nano silica the hardness became 30 , with magnetic nano particles the hardness became 30-35 and the treatment with carbon nanotube the hardness became 69 so there is an improvement in hardness after treatment with nano-materials (Figure 3) (Table 2).

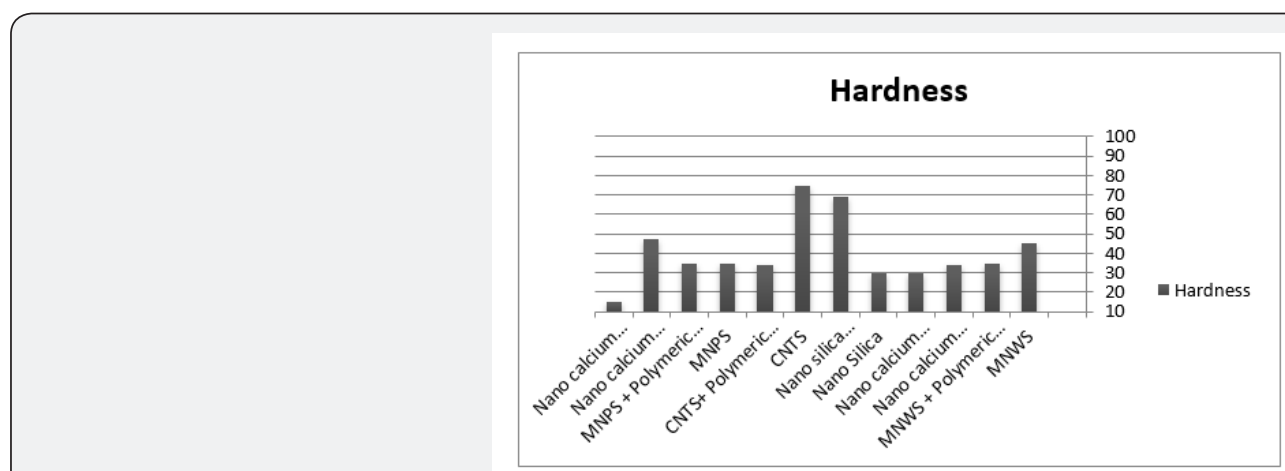

Figure 3: The results of measurements using shore D.

Table 2: The relation between penetration and newton force.

\begin{tabular}{|c|c|c|c|c|}
\hline The kind of treatment & The samples & $\begin{array}{c}\text { During } \\
\text { measurements }\end{array}$ & The description & The results \\
\hline Untreated sample & & & Medium Hard & $19-15$ \\
\hline $\begin{array}{l}\text { Nano calcium } \\
\text { hydroxide + Polymeric } \\
\text { material }\end{array}$ & & & Hard & 47 \\
\hline $\begin{array}{l}\text { Nano calcium } \\
\text { hydroxide }\end{array}$ & & & Hard & 45 \\
\hline $\begin{array}{l}\text { MNPS + Polymeric } \\
\text { material }\end{array}$ & & & Hard & 35 \\
\hline MNPS & & & Hard & 34 \\
\hline $\begin{array}{l}\text { CNTS+ Polymeric } \\
\text { material }\end{array}$ & & & Extra Hard & 75 \\
\hline CNTS & & & Extra Hard & 69 \\
\hline $\begin{array}{l}\text { Nano silica } \\
\text { +Polymeric material }\end{array}$ & & & Hard & 30 \\
\hline Nano Silica & & & Hard & 30 \\
\hline $\begin{array}{l}\text { Nano calcium } \\
\text { carbonate+ Polymeric } \\
\text { material }\end{array}$ & & & Hard & 45 \\
\hline $\begin{array}{l}\text { Nano calcium } \\
\text { carbonate }\end{array}$ & & & Hard & 34 \\
\hline $\begin{array}{l}\text { MNWS + Polymeric } \\
\text { material }\end{array}$ & & & Hard & 35 \\
\hline MNWS & & & Hard & 45 \\
\hline
\end{tabular}




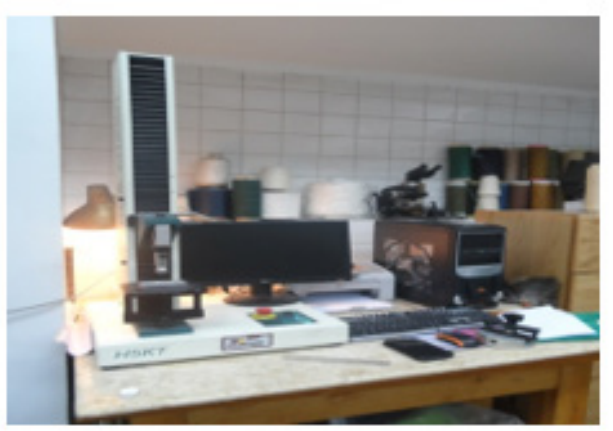

Figure 4: The Tinuis Olsen instrument In National Institute of Measurement and Calibration.

Bursting Strength: The bursting strength is express the ability of the mural paintings to bear the out pressure to be broken so that test is revisable. Currently in this paper Tinuis Olsen H5KT machine was designed for using in Research and Quality Control to measure material's strength and performance. All tests are designed and implemented by Tinius
Olsen in accordance with key international testing standards including ISO [6], ASTM, EN and other industrial standards. The load measurement accuracy: $+/-0.5 \%$ of applied load from $2 \%$ to $100 \%$, and position measurement accuracy: $+/-0.01 \%$ of reading or $0.001 \mathrm{~mm}$ [7] (Figure 4).

a. The pressure strength for the samples before treatment in range 248-250 newton

b. The nano silica and calcium carbonate filled the gaps inside the interior structure the bursting strength 300-400 newton.

c. Treated models with magnetic nano particles and magnetic nano wires the bursting strength in range 300-350 newton.

d. The treated model with carbon nano tube the bursting strength increased to 600-650.

e. The treated model with nano calcium hydroxide the bursting strength improved to be in range 400-550 newton. (Figure 5) (Table 3)

Table 3: The results of bursting strength.

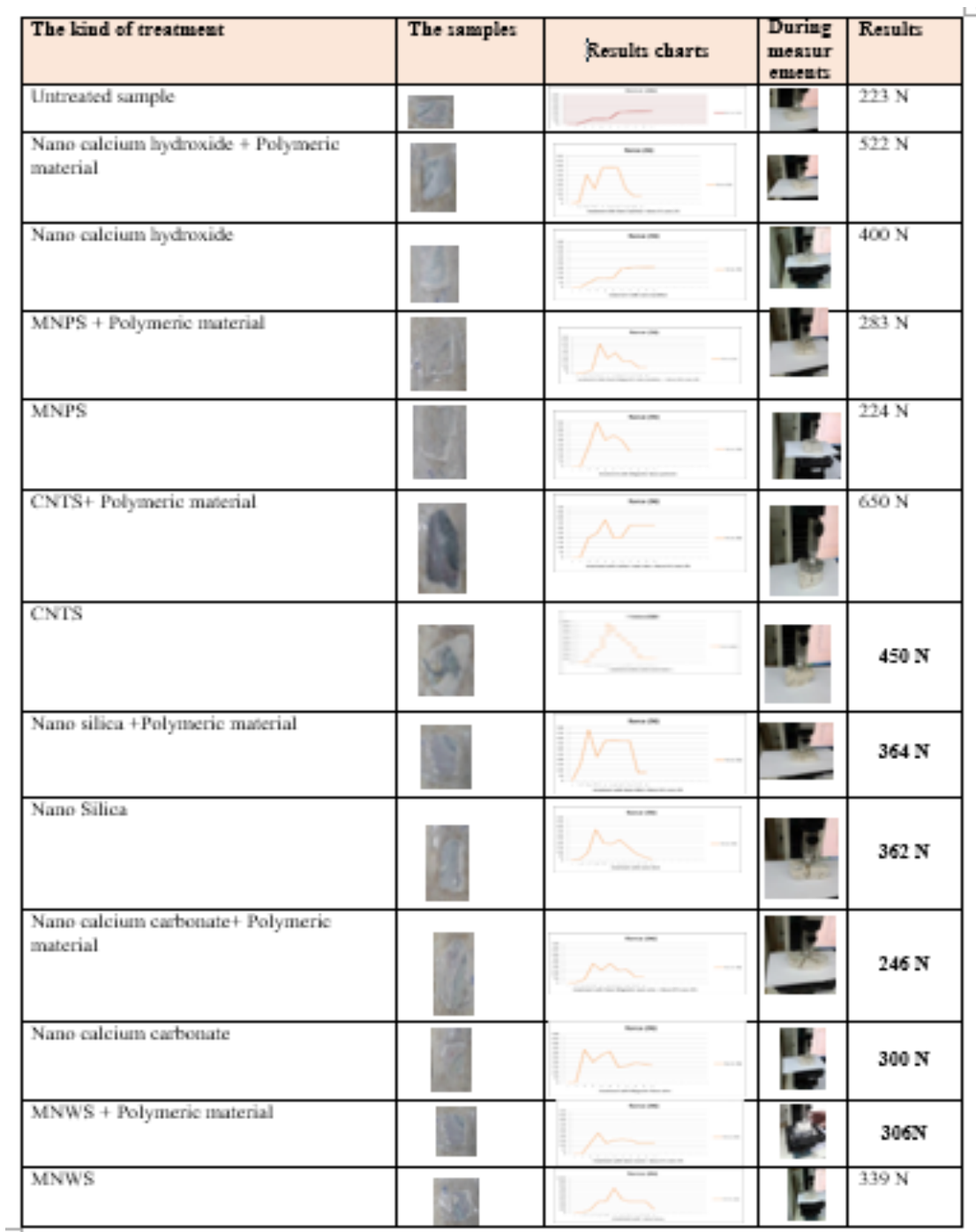




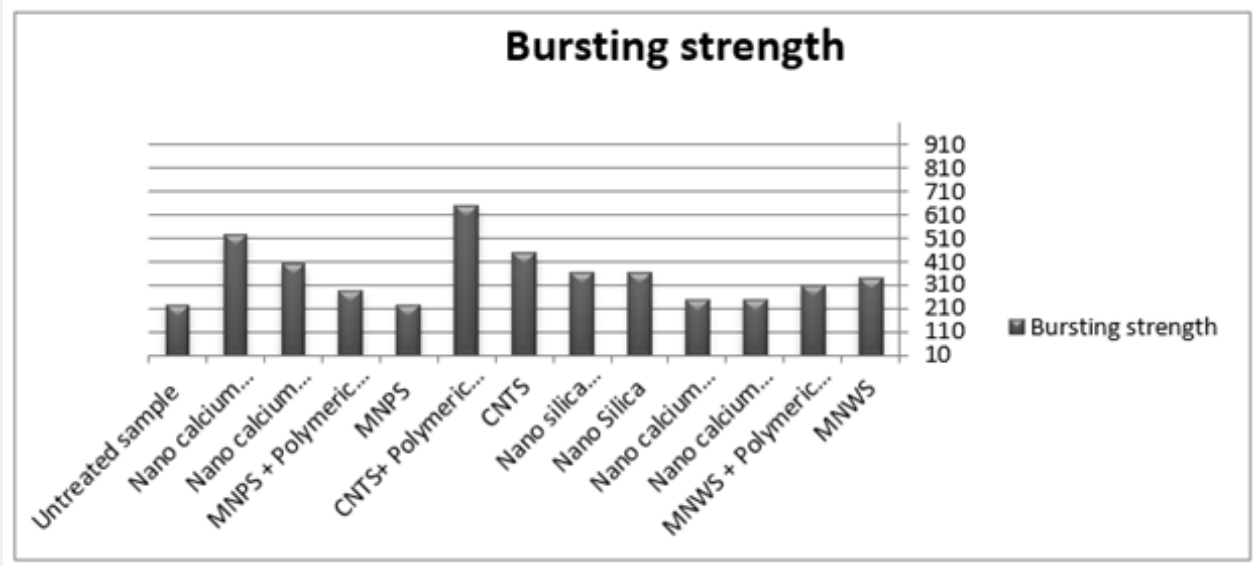

Figure 5: The bursting strength results.

\section{Conclusion}

In studies of the behavior of nanomaterials in consolidation mockup models prepared only to make a comparison under specific conditions as Hardness and bursting strength. There are a very wide range between sample before treatment and after treatment with nanomaterials which proved that an improvement happened in the treated models because of nanomaterials which filled gaps, according to nano-calcium hydroxide which combines with carbon dioxide forming calcium carbonate

\section{References}

1. Giorgi R, Baglioni M, Berti D, Baglioni P (2009) New Methodologies for the Conservation of Cultural Heritage: Micellar Solutions. Microemulsions, and Hydroxide Nanoparticles, Account of Chemical Research pp. 605-704.
2. Berger GA (1975) Heat-Seal Lining of a Torn Painting with BEVA 371. Studies in Conservation 20(3): 51-125.

3. Carretti E, Chelazzi D, Rocchigiani G, Baglioni P (2013) Interactions between Nanostructured Calcium Hydroxide and Acrylate Copolymers, Implications in Cultural Heritage Conservation pp. 9881-9890.

4. Kopeliovich D (2013) Requirements to engine bearing materials, www. substech.com.

5. Sližkova Z, Drdacky M (2014) Testing of treatment effects of nano sols on selected porous historic materials, Journal of Cultural Heritage $p$. 1- 4

6. http://www.tiniusolsens.com/products/bench-machines/benchh5k-t.html

7. Sližkova Z, Drdacky M (2014) Consolidation of weak lime mortars by means of saturated solution of calcium hydroxide or barium hydroxide. Journal of Cultural Heritage p. 1-9.

\section{Your next submission with Juniper Publishers will reach you the below assets}

- Quality Editorial service

- Swift Peer Review

- Reprints availability

- E-prints Service

- Manuscript Podcast for convenient understanding

- Global attainment for your research

- Manuscript accessibility in different formats

( Pdf, E-pub, Full Text, Audio)

- Unceasing customer service

Track the below URL for one-step submission https://juniperpublishers.com/online-submission.php 